\title{
INSTAGLISH: WHEN INSTAGRAM IS BEYOND ONLINE PHOTO- SHARING PLATFORM TO INDUCE YOUR ENGLISH
}

\author{
Pusfika Rayuningtya \\ STT Stikma Internasional \\ pusfikar@yahoo.com \\ Ika Fitriani \\ STT Stikma Internasional \\ iiekafitri@gmail.com
}

\begin{abstract}
Motivated by the growth of social media throughout the globe, including in Indonesia, educational practitioners need to be creative and make use of this opportunity to boost up the learning goals, for example making use of Facebook, Twitter, Instagram, Line, and many others (social media) in educational settings. Among those social media, Instagram has increased its popularity, particularly in Indonesia, with its 22 million users. It is an online platform in which users are able to share their stories via uploaded photos. Recently, it is not merely used as photo story sharing but also online shopping, news updating, and video conferencing. As Instagram offers promising features, this study explored how this platform was applied to improve the students English written competence, focusing on reading and writing. This study is action research that investigates the use of Instagram as a social-andeducational medium that offers beyond new language learning experiences in the project called InstaGlish, Instagram English. The data were collected from the classroom observation during the project, students' Instagram photo posts along with the captions and comments, as well as students' reading and writing scores after project implementation. Questionnaire and direct interview to the students were also carried out to give a more thorough and deeper understanding of the students' responses toward how effective InstaGlish helps them learn and induce their English. In addition, the findings of this current study were expected to give fruitful insight on how to use social media not merely as the fun-without-meaning activity, yet fun-andmeaningful new learning experiences.
\end{abstract}

Keywords: Instagram, InstaGlish, social media, learning media

\section{A. INTRODUCTION}

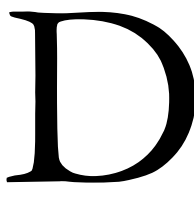

igital revolution has developed digital society and transformed many aspects of

human's life. The emergence of social media has played a vital role in connecting people which highly impacts the education field. Technology in pedagogical practices can facilitate personalized and flexible learning of millennial youth that are active and enthusiastic in the digital world (Lonka et al, 2015). Further, implementation of technology is not merely in the form of computer-based but more on socio digital participation, such as using social media and/or search engines within the classroom to support learning activities so that it promotes 21 st century skills such as (digital) literacies, creative problem solving skills, collaboration and communication skills, cultural and ethical awareness and entrepreneurship.

The shifting from traditional toward digital instruction where social media is used as the 
medium of instruction is supported by the global significant increasing number of social media users. In Indonesia, based on the survey in 2016 conducted by Asosiasi Penyelenggara Jasa Internet Indonesia, 132.7 million out of 256.2 million are active internet users with approximately $89.7 \%$ penetration toward college students. The survey also found out that $97.4 \%$ users use it for accessing social media, such as Facebook (54\%), Instagram (15\%), and Youtube (11\%). As this paper concerns, Instagram is on the second rank of social media accessed by 19.9 million. In line with the data mentioned, global data obtained from Omnicorecom updated in January 2017 , stated that $20 \%$ of all the Internet users (600 millions) are active users of Instagram with $28 \%$ of the Internet users between the age of 18 and 29 use Instagram and $17 \%$ of teens say Instagram is the most important social media site (Aslam, 2017). Regarding this fact, inserting Instagram within the instruction process will bridge the challenge of the digital era and educational goal.

Instagram, in fact, is getting popular as a social picture-sharing platform that can be used for sharing selfie pictures and beyond, inter alia for valuable social networking resources, even uniquely facilitating teachers and students to connect and share information (Katey, 2015). The presence of Instagram as popular social media among millennial youth can be embedded in the classroom; teachers can creatively use Instagram with their students for educational benefits, for example students are assigned to document classroom activities, projects, field trips, and upload it in the Instagram. Teachers can also share examples of projects and activities in the classroom, document students' work and label their photos with relevant hashtags so that others will also be able to access them for teaching inspiration.

Regarding the potential use of Instagram in the educational setting, it can be revolutionized by making use of photography with engaging activities in the classroom (Cunningham, 2014). One of the alternatives of applying Instagram within the classroom of English as Foreign Language (EFL) could be in the form of posting photos/videos and adding captions to include key facts or information, stories, thoughts, opinion, or social comment to accompany uploaded images and/or video instead of writing traditional research papers or narrative essays-which is difficult for EFL learners. Instagram can be used to help students learn foreign languages and be the way for teachers to boost students' language learning autonomy as students are required to be active in finding the images/videos to be uploaded and thinking over the captions they are going to use along with the visual.

Many previous researches that incorporated Instagram to the teaching and learning process showed positive results (Handayani, 2016; Manaroinsong, 2018; Erarslan, 2019). It is proven to positively impact the students' classroom achievement in improving their English 
skills and supplementary independent learning for students. Instagram also gives English exposure to the students as there are a lot of educational accounts that students can follow (Manaroinsong, 2018). The main difference between the previous studies and this research is the methodology. Previous studies (Manaroinsong, 2018; Erarslan, 2019) employ mixed methods by analysing the data from questionnaires distributed, while this research applies the classroom action research (CAR) method. Handayani (2016) discussed the use of social media, particularly Instagram, that has some positive impacts on the language learning process. The discussions can be as supporting theories for this present study.

On the other hand, looking at the real-life learning condition of students at STT STIKMA Internasional Malang, they have difficulty in writing. It was found out that the students' writing work consists of errors in terms of grammar, mechanics, and content. Often, the students utilized Google Translate to make sentences, which leads to the Indonesian-context sentences. Some students also have difficulty expressing their opinion regarding a specific topic given by the teacher. The idea of opinion structuring in sentences and paragraphs within the classroom context is considered dull and limited by time. They need longer time to structure a few sentences during the teaching and learning process in the classroom. This fact leads to the unfinished writing task when it is assigned in the classroom. Students also have problems in using the correct punctuation and capitalization in their writing work. Thus, it disrupts the flow of their sentences or paragraphs.

Grounding from these numerous merits Instagram possesses and the problem that happens in real classroom context (STT STIKMA Internasional Malang), the researchers utilized Instagram as the teaching medium along with the concept of socio digital participation in the classroom to improve the students' English competence, particularly writing skill in the project called "InstaGlish". InstaGlish, an abbreviation of Instagram English, is an online English project based on Instagram application that is aimed to improve students' English competence. Also, the fact that most students have Instagram accounts so it eases the monitoring of project's progress. Besides, InstaGlish was conducted to conduct learning autonomy as an enrichment activity to go side by side with the classroom session that is carried out once a week. This current research is objected to investigating "how to improve students' writing skill through the application of InstaGlish project". This paper, further, is intended to discuss the project in detail to digest the insight of the Instagram insertion in the process of foreign language learning and classroom instruction. 


\section{B. REVIEW OF LITERATURE}

In conducting the teaching and learning process, teachers must be creative in applying learning media to the maximum use. Learning media, as well as strategies, is claimed successfully in increasing students' motivation and thus attract students to learn more (Puspitarini \& Hanif, 2019; Musfiqon, 2012). With the implementation of learning media, students will be able to understand the topic easier and can relate to real-life learning as they have first-hand experience in using the media. This is supported by Dale in Daryanto (2013) that showed the Cone of Experience figure where students' concrete experience leads to the highest learning outcomes.

In the era of education 4.0, the advancement of technology has transformed every aspect of life, including educational contexts. The use of technology based learning media allows students' learning independence, productivity, acceleration, and feedback (Husain in Puspitarini \& Hanif, 2019). The emergence of social media in which social interaction can be done using the help of technology also has the potential to advance the process of teaching and learning. Among hundreds of social media, Instagram becomes the most users per January 2021 (Tankovska, 2021). It earns the fifth place just behind Facebook, YouTube, and WhatsApp. This data shows how people are still attracted to the application amidst all the emergence of new social media. As the application popularity grows bigger, the use of Instagram is not limited to entertainment-use only, but also to the use of media for teaching within the classroom context. Instagram can be a good teaching medium to use that makes the educational process become interesting, insightful, and unique (Kirst in Handayani, 2016).

This makes sense as Instagram offers a fun way of learning where they can exchange comments with their friends through the posts they make. By leaving comments, students learn writing indirectly which leads to a different experience than when they are asked to write in a book within a classroom setting. Not only that, Instagram also allows students to express their thoughts about something by writing a post's caption. In a study conducted by Erarslan (2019), it was strengthened that Instagram had a positive impact in terms of students' achievement scores on language learning so that it can be applied to enhance learning of English both as supplementary as well as formal teaching through exposing the students to the target language. Further, Erarslan study claimed that Instagram enables students to create a cooperative, collaborative, interactive learning to support formal classroom setting. Another study conducted by Manaroinsong (2018) with non-English department students supported that instagram is able to be used as mobile learning to support their English cognitive learning process through searching and following numerous educational accounts and also improve 
their language skills by doing independent learning activities such as reading, listening, and creating Instagram posts in English language.

Knowing the popularity of Instagram and its availability as an educational tool, researchers think of how to incorporate Instagram to the process of teaching English for higher education. This is when the researchers implement the project of InstaGlish, an abbreviation of Instagram English. Through the use of InstaGlish, the researchers shifted the conventional book writing activity to social media to create a new fun learning. Social media helps new generations in learning, motivating, and improving English (Belal, 2014). InstaGlish also allows students' creativity in participating in the project by posting pictures and creating videos which are posted to their respective accounts. Other students, then, are allowed to comment on the friends' posts by giving suggestions, questions, or opinions. This way, the interaction between students is more natural and it is not limited within the classroom context only.

\section{METHOD}

This current study applied collaborative action research. The researchers investigated the problems in the classroom, reviewed a number of references to solve the problems, planned the action, did action research to improve the teaching and learning activity in the classroom, observed the results, and did reflection whether or not the action was successful. The process of research applied to Kurt Lewin (1940, in McKay 2006:30) CAR cycles which are fourstage-action cycles which are named Planning, Acting, Observing, and Reflecting. The cycle is illustrated in the Figure 1 as follows:

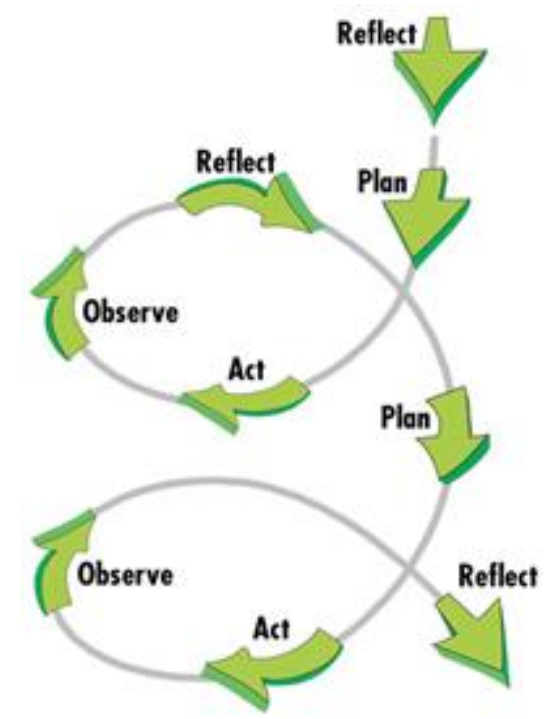

Figure 1. The Cycle of Action Research (adapted from Rayuningtya, 2013) 
The participants of the current research are students of STT STIKMA Internasional Malang in the second semester majoring in Information and Technology (IT). In total, there are 24 students ( 3 females and 21 males). Based on the preliminary observation carried out by the teacher during ongoing teaching and learning in the classroom, it was found out that the majority of students had low motivation to learn English. It was proven by the students who were dispassionate in being active during the lesson. Another problem which was apparent is the misspelling that was often found in students' written work. Before the InstaGlish project was started, the teacher conducted a pre-assessment to investigate students' writing skills. The result showed that there were many misspellings in students' work; it was not only limited to the unfamiliar words but also to the common daily words.

Prior to the implementation of the InstaGlish project, the researchers set up the criteria of success to determine the success of the project implemented. There were two criteria of success in this current project which were students' score representing their writing skill improvement and students' participation inside (during) and outside the class. The researchers used scoring rubric which covered content, grammar, and mechanics to assess students' writing skill. Meanwhile, students' participation was assessed using classroom observation conducted by the researchers throughout the project as well as questionnaire given after the cycle 1 to unearth students' responses toward the project of InstaGlish. A cycle was categorized successful if more than $50 \%$ of the students were active inside and/or outside the class and/or if more than $50 \%$ of students could meet the minimum passing grade of "C".

The data were collected from pre-project questionnaire to investigate the students' social media usage and the potential of Instagram to be used within instruction, classroom observation to assess the students' activeness during the project, pre assessment to understand the initial competence of students' writing skill, post-project questionnaire (after Cycle 1) to examine students' responses toward the implementation of InstaGlish project, formative assessment (after the Cycle 1) to get the insight of students' English improvement, students' uploaded pictures along with the captions (Cycle 1,2, and 3) to get the conclusion on the application of Instagram in learning English as a foreign language in the classroom context, and summative assessment to collect the data on students' writing skill which was analyzed to examine the students' improvement and how well the project of InstaGlish affects their English skill and classroom performance.

The process of the InstaGlish project was divided into three cycles. It was started in cycle 1 where all students were required to have Instagram account and had obligation to upload three pictures along with three captions using their own Instagram accounts and hashtag 
\#InstaGlishsttstikma. The cycle 1 was carried out in five weeks in which a theme was provided each week. In this cycle, the researchers also monitored the interaction between the students through the comments in other students' posts. At the end of this cycle, there were three winners chosen for The Best Picture, The Best Caption, and The Most-Liked Picture who were appreciated by prizes.

After analyzing the result of cycle 1, the researchers went to cycle 2 for another five weeks by applying some changes on the procedure of the InstaGlish project. In the cycle 2, the researchers posted one picture in each week to the researcher's Instagram account by using hashtags \#InstaGlishsttstikma and \#InstaGlishmakeacaption. Students were assigned to check the researcher's Instagram account and create a caption for the picture uploaded via comment below the picture weekly. In this cycle, the project was not obligatory or in other words students were free to or not to participate in giving captions. It was expected that the researchers would get the data of the students with high and low motivation in doing the project. During this cycle 2, the researcher had a weekly winner as Caption of the Week who was appreciated by prize and photographed to be posted in the researcher's Instagram account.

After analyzing the results of cycle 2, the researchers continued to cycle 3 for three weeks. In this cycle, the researchers uploaded the pictures a day before the class schedule and the students created the captions directly during the class. The pictures' themes used were back to nature (garden), Indonesian education face, and Puss in Boots. In this cycle, the students were expected to be more aware of grammatical structure and how to compose sentences, to increase range of vocabulary, and to show improvement in writing both for high and low motivated students.

The summary of InstaGlish implementation applied throughout project is shown in Table 1 as follows:

Table 1. Summary of Three Cycles of InstaGlish Implementation

\begin{tabular}{llll}
\hline & Cycle 1 & Cycle 2 & Cycle 3 \\
\hline Length & 5 weeks & 5 weeks & 3 weeks \\
\hline What to Do & $\begin{array}{lll}\text { Students are obligatory } \\
\text { uploading three photos } \\
\text { each week }\end{array}$ & $\begin{array}{l}\text { Students are given freedom } \\
\text { to participate giving } \\
\text { caption on the picture } \\
\text { uploaded by the } \\
\text { researchers }\end{array}$ & $\begin{array}{l}\text { Students are asked to } \\
\text { create caption directly } \\
\text { during the classroom } \\
\text { session and do peer } \\
\text { assessment }\end{array}$ \\
\hline Theme & $\begin{array}{lll}\text { Food, Favorite Things, } \\
\text { Nature, Idols, Favorite } \\
\text { Songs }\end{array}$ & $\begin{array}{l}\text { public transportation } \\
\text { drivers strike, mobile } \\
\text { phone over usage, }\end{array}$ & $\begin{array}{l}\text { back to nature (garden), } \\
\text { indonesian education face, } \\
\text { puss in boots. }\end{array}$ \\
\hline
\end{tabular}




\begin{tabular}{|c|c|c|c|}
\hline & & $\begin{array}{l}\text { cyberbullying, } \\
\text { online shopping, } \\
\text { game addiction }\end{array}$ & \\
\hline Goal & $\begin{array}{l}\text { Familiarize students in } \\
\text { uploading pictures with } \\
\text { English captions. } \\
\text { Developing students' } \\
\text { writing skill } \\
\text { Promote students' learning } \\
\text { autonomy } \\
\text { Building students' character } \\
\text { of being punctual }\end{array}$ & $\begin{array}{l}\text { Assess students' motivation } \\
\text { in learning English. } \\
\text { Developing students' } \\
\text { writing skill } \\
\text { Promote students learning } \\
\text { autonomy. } \\
\text { Building students' character } \\
\text { of being punctual }\end{array}$ & $\begin{array}{l}\text { Developing students' } \\
\text { grammatical structure use } \\
\text { in writing skill }\end{array}$ \\
\hline Rewards & $\begin{array}{l}\text { Nomination of The Best } \\
\text { Picture, The Best Caption, } \\
\text { and The Most-Liked } \\
\text { Picture who were } \\
\text { appreciated by prizes at the } \\
\text { end of the cycle } 1\end{array}$ & $\begin{array}{l}\text { Weekly winner nominated } \\
\text { as Caption of the Week }\end{array}$ & None \\
\hline
\end{tabular}

At last, the researchers came to the data analysis stage. The data triangulation that was aimed to provide validity was conducted by collecting all the data, such as student pre-project questionnaire assessment result, students' behavior observation throughout the InstaGlish project implementation, pre-assessment activity before the project, post questionnaire on the students' responses on the application of InstaGlish project after cycle 1, students' uploaded pictures and caption from Cycle 1, 2, and 3, formative assessment after first cycle, summative assessment in conducting the InstaGlish project.

\section{FINDINGS AND DISCUSSION}

\section{Pre-Project Questionnaire}

Before conducting the InstaGlish project, the researchers distributed questionnaires to investigate the usage of social media by the students and the prospect of Instagram to be used for research instruction. The questionnaire consists of twelve questions which most of them are Instagram-related. The result showed that all students have social media accounts, either it is Facebook, Twitter, or Instagram. However, only 58\% students joined Instagram which became one of the challenges in conducting the project as some students were not familiar with Instagram features. Regarding this issue, as the project was obligatory to all the students in the class, all students were asked to create an Instagram account so that they will be able to join the project.

The questionnaire was also objected to collecting the data about students' activities on Instagram. Aside from posting the pictures, most of the students $(58 \%)$ mentioned that they 
usually gave comments and likes toward other people's posts. They also stated that they obtained the up-to-date news from Instagram. Shifting to the use of Instagram caption, $42 \%$ of the students do not make a caption while posting their pictures. In addition, $42 \%$ of them read other people's captions when accessing Instagram. It also applies if the caption is in English as $50 \%$ read the caption thoroughly. Most of the students stated that they utilize Instagram as the learning medium to find the news and information, video tutorial, and new places to visit. $8 \%$ of the students added that Instagram could be used for learning English. $58 \%$ of the students agreed that applying Instagram in the teaching and learning process inside the classroom could be an interesting way. Regarding the positive results from the preproject questionnaire, the researchers concluded that Instagram could be very potential to be applied in the classroom activities to induce students' English.

\section{Pre-Assessment}

Pre-assessment was conducted to understand the initial competence of students' writing skill. The students were given two pictures on the topics of self-camera and hoax through Power Point Presentation during the teaching and learning process in which they had to create a caption for each picture in five sentences. After analyzing the students' written work, numerous errors were found such as from the grammar, mechanics, and content.

The grammar refers to the language structure used in constructing English sentences. From this aspect, a lot of errors were found from the conjunction, sentence structure (none of the subject and verb in a sentence), and subject and verb agreement. It was found out that sentence structure dominated the grammatical errors by $85 \%$. Coming in the second and third places were subject and verb agreement with 54\% and conjunction with 54\%. These problems were caused by the direct translation from Indonesian sentences to English. From the observation, the researchers noticed that most of the students used Google Translate to translate their Indonesian sentences to English. While it could be correct at times, the direct translation often leads to the grammatically wrong sentences; as it sounds very Indonesian. The sentences were incorrect grammatically in English as the students translated word by word by using Indonesian system in constructing sentences, whereas English and Indonesian are different in some points.

There were also a lot of errors in writing mechanics. This aspect covers the technicalities of written work like spelling, punctuation, capitalization, etc. The students made numerous misspellings in writing English words. In addition, the use of capitalization was rare to be applied in their written work. The students applied small-case letters in the beginning of the 
sentences. The punctuation was also another problem, for instance students did not use any punctuation in the right place and often did not use them at all. Both punctuation and capitalization dominated the mechanical errors by $77 \%$. Misspelling from the students' work was represented by $85 \%$.

The last aspect to be considered is content. The content refers to the information presented by the students in the written form. As the students were shown two pictures of selca and hoax picture-related, they were expected to write a caption which had connection with the pictures; either describing the picture, telling their own story which was still related to the picture, expressing opinion towards the picture, or impersonating people in the picture as themselves. While $83 \%$ of the students did well, there were two students whose writing did not represent the picture. Rather than explaining the picture shown, a student mentioned several news headlines in their written work. Another student explained the selca picture with something that has no relation with the action of taking a self-camera itself.

\section{InstaGlish Project Implementation Cycle One}

This present research was conducted in three cycles within 13 weeks. The first cycle was conducted in five weeks in which the students were asked to post three pictures every week to Instagram along with the caption. Given the topics by the researchers, the students were expected to explore more on the different topics each week. This activity was also fun and students-centered learning as students can post the pictures they like, yet they still had to follow the topic given. The researchers also created several rules such as the students were prohibited to copy and paste captions from the Internet, students had to use their own picture to upload, the students were prohibited to use special applications to get more likes on Instagram, and the students were asked to write at least 6 sentences for the caption.

The results of the first cycle showed that the majority of the students were excited to participate in the InstaGlish project as they can share their stories and experiences through the pictures. It was shown that $17 \%$ of students said that InstaGlish can be their sharing medium. The opinion that InstaGlish can be a good learning material was $33 \%$. The fact that they were interested in the project did not make it run smoothly without any challenges. Some challenges faced such as cheating, passive participation, and unpunctuality in posting the pictures. It was found out that $64.7 \%$ out of the students' total number was not punctual toward the due of the tasks.

The first cycle highlighted the students' low writing ability. While the students were 
assumed to grasp the background knowledge of the topics in the first cycle of InstaGlish, it was found out that the results were still poor. Based on the students' opinion, they have difficulty mostly in making caption due to lack of vocabulary as the knowledge of word plays a vital role or key in language comprehension or the success of foreign language learning (Ferreira, 2007). It is understandable since many students were not accustomed to writing English sentences on a daily basis due to the position of English as a foreign language. It was only used within the classroom context so that the exposure is quite minimum. Beck et al. (2002) and Juel et al. (2003) in Pikulski and Templeton (2004) mentioned that there was never enough for children to overcome their vocabulary weakness based on what they received in school. It must be noted that Indonesian students were not exposed much to English since they were young. Moreover, the position of English in the university level which is merely as Mata Kuliah Umum lowers students' motivation in learning English.

The fact showed that students still made errors in constructing sentences correctly as they did not use subject. The students also fully adopted the way to write Indonesian sentences to English, i.e. using Google Translate which resulted in grammar errors. The students were also found using few Indonesian words in their written work, both in their caption and class' written assignment. In other words, they mixed English and Indonesian languages at once. Another difficulty was the spelling which played a crucial role in students' errors. The students were clueless in spelling some unfamiliar words. Even though the topics given were simple, some students thought it would be hard to choose the pictures to post on Instagram. Cycle 1 accentuated students' low writing ability, there were found writing improvement for several students. The major improvement shown was vocabulary. From the questionnaire distributed after cycle 1, it was figured out that they improved their vocabulary, politeness, grammar, spelling, knowledge, and the courage in expressing their thoughts. The summary of students' improvement is shown as follows in Figure 2.

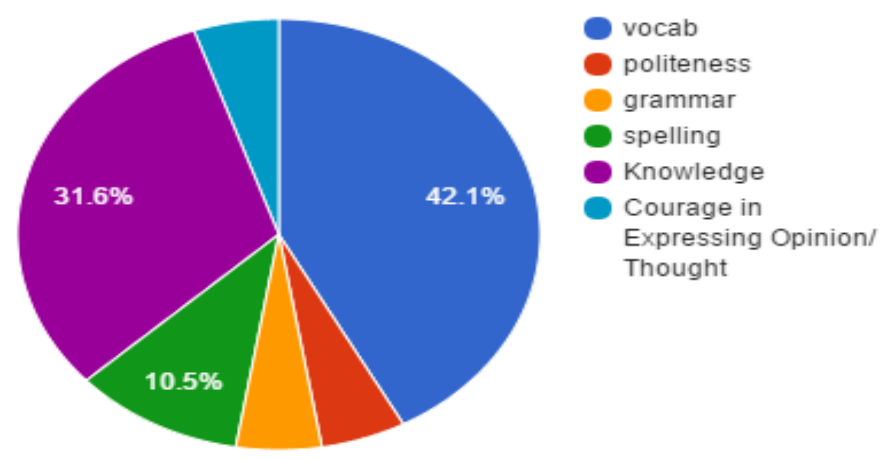

Figure 2. Students' Improvement during InstaGlish Project Implementation 
From the cycle one, the students mentioned several reasons they like InstaGlish, e.g. InstaGlish could improve their English and vocabulary, they could also post the pictures they liked, created interesting captions, and had interaction with others as shown in Figure 3.

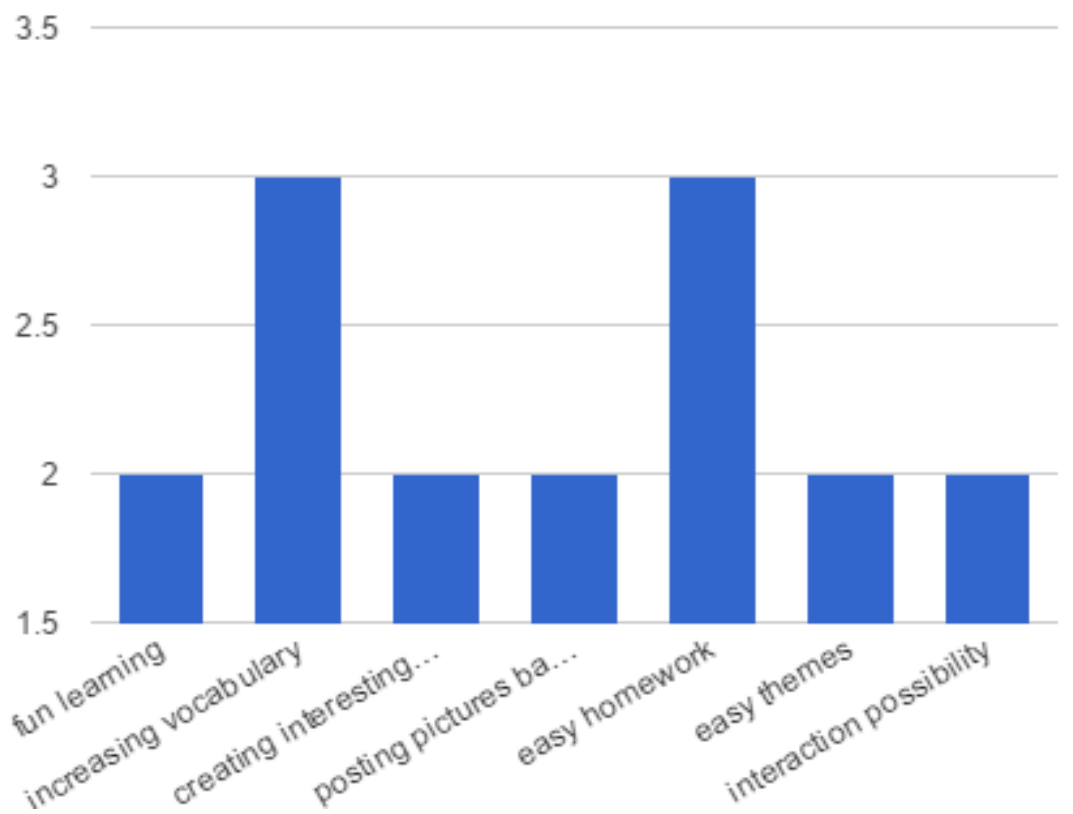

Figure 3. Students' Opinion about InstaGlish

Most students also stated that there was none to dislike from InstaGlish. Only a few students mentioned the caption, theme, topic, internet connection needed, and number and quality of pictures uploaded as the aspects they dislike from InstaGlish. The graphic on the students' responses toward what they dislike from InstaGlish is displayed in Figure 4.

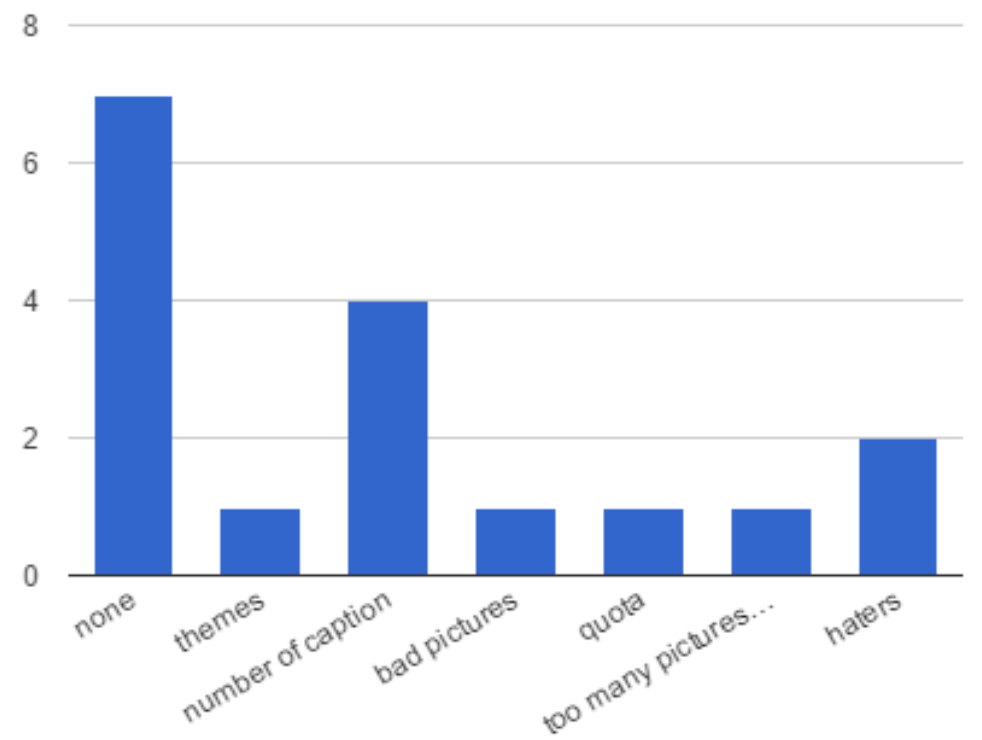

Figure 4. What Students Dislike from InstaGlish 
At the end of cycle 1, the researchers gave appreciation toward three students to win the three nominations as Best Caption, Best Picture, and Most-Like Picture. The Best caption nomination was intended to the student who could create interesting caption which closely related to the pictures uploaded with minimal grammatical errors, the Best Picture nomination was intended to the student who had uploaded unique, beautiful, original and meaningful pictures, and the Most-Liked Picture nomination was for student whose picture got the most like. The winners of the Best Caption, the Best Picture, and the Most-Liked Picture were shown in Figure 5.

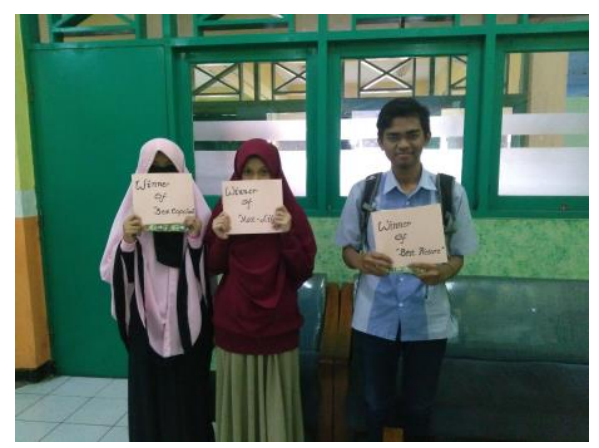

Figure 5. The Winners of the Best Caption, the Best Picture, the Most Liked Picture

\section{Formative Assessment}

After conducting cycle 1, the researchers carried out formative assessment by asking the students to write two paragraphs - six sentences for each, about their favorite online shopping website and their reasons why they chose it. The results showed that there was improvement shown compared to the period when the InstaGlish project was enacted. The researchers analyzed the writing based on three aspects which were grammar, mechanics, and content.

From the grammar aspect, there were errors found in all students' work. The ultimate error was the sentence structure because of the lack of subject and verb $(88 \%)$. Another error was subject and verb agreement where $76 \%$ of the students forgot to add 's/es' after third person singular. Another grammatical error was conjunction in which $47 \%$ of the students used the conjunctions in the beginning of the sentences instead of positioning it in the middle of two sentences to connect them. Then, the second aspect to consider was mechanics which covered spelling, capitalization, and punctuation. Some students, as in $41 \%$, used incorrect spelling in writing English sentences. There were also numerous errors in terms of capitalizations $(65 \%)$ and punctuation (41\%). From the content aspect, there was an improvement compared to the pre-assessment as $88 \%$ of the students stayed on the topic given. 
After analyzing the result of cycle 1, the researchers concluded that the students still faced difficulty in writing because of a number of errors in grammar, mechanics, and content.. There were $29 \%$ students who passed the minimum passing grade, which was lower than the criteria of success of more than $50 \%$ having to reach minimum passing grade C. Another major challenge was that most of the students were passive during the project. They rarely had the initiative to ask or discuss something to the researchers inside or outside the class. As mentioned before, the cycle will be successful if more than $50 \%$ of the students show active participation inside and outside the classroom and Cycle 1 showed that only $8 \%$ of the students were active so that the researchers decided to conduct the cycle 2 to improve the students' activeness as well as students' writing skill. In addition, it was also expected as the medium for the students to practice writing more in English.

\section{Cycle Two}

The second cycle of InstaGlish was conducted for five weeks in length with a number of changes applied. Here, the students created captions based on the pictures that the researchers posted on Instagram. The caption that students needed to create was posted via comment below the pictures. In this cycle, there would be a winner in each week for the nomination Caption of the Week and the winner would be given a prize. The prize was presumed to be as a stimulus for the students so they could do better in creating the caption. To be underlined, the cycle 2 was not an obligatory-student could decide to either comment or not. It was intended to examine which students had high and low motivation in learning English as well as the students' active participation.

From Cycle 2, there were 62\% from all students participating. As mentioned above, Caption of the Week was chosen each week so in total there were five winners during Cycle 2. These five students showed their active participation in Cycle 2 by creating captions more than once. Cycle 2 was also analyzed using the same rubric assessing three aspects of students' work which were grammar, mechanics, and content.

From grammar, errors were noticeable in terms of conjunction because $75 \%$ students still used and, but, so in the beginning of the sentences. There were $73 \%$ students who had problem with sentence structure due to lacking of subject and verb in their sentences. Subject and verb agreement came in the third with 67\%. At last, 56\% errors were found in passive form sentences. From the mechanics, the misspelling (53\%) was recognized from students' work such as gamer to gamet, stopped to stoped, and causes to couses. Punctuation and capitalization were coming in second and third with 53\% and $47 \%$. From the content, $88 \%$ stayed in topic by 
creating caption which was related to the pictures. Comparing with the criteria of success, students' active participation was a crucial consideration for the researchers to continue to the next cycle. Although there were more than $50 \%$ of the students participated in Cycle 2, only $33 \%$ has created caption via comment more than once. From the score, it was also found out that only $33 \%$ students reached the minimum passing grade $\mathrm{C}$. Therefore, the researchers decided to continue to Cycle 3 with a slight of differences in method of project application by asking the students to assess their own written work.

\section{Cycle Three}

After investigating the result of cycle 2, the researchers decided to go forward to cycle 3 that was conducted in three weeks and was obligatory to all students. The difference between cycle 2 and 3 was that students created the caption from a short movie played during the class and did peer-assessment. Because of the time limitation of writing during the English class period, the students did not write in class but commented via Instagram below the playedshort-movie picture that the researchers uploaded. Thus, the assessment was conducted by the researchers instead of the students.

Based on the observation in class, it was found out that the students needed a long time to write one paragraph of caption which consisted of five-six sentences, approximately 30-35 minutes. In order to help students write the caption, the teacher taught mind mapping to ease students in generating the idea. The researchers taught mind mapping for writing in class by giving the students a specific topic. The process of brainstorming the ideas during mind mapping was fast and effective. The researchers also taught the students to create complete and simple sentences consisting of subject, verb, and object. The researchers taught this because the students tend to create long sentences which often consisted of several clauses, both in Indonesian and English. Consequently, the students found difficulty in transferring the information they had during mind mapping to written form. By teaching how to create complete and simple sentences, the students were expected to express their opinion towards the pictures easily. At the end, the result showed that students used simpler and shorter English sentences compared to previous cycles, yet more understandable.

In addition, it was found out that the students were busy translating their work literally from Indonesian to English. In fact, Indonesian and English have a number of differences which could lead to the incorrectness of translation. According to Teti, et. al (2016:3), two of characteristics which differentiate Indonesian and English are plural forms and possessive pronouns. This is why there were few mistakes regarding the plural forms in students' work. Some students did well in translating their work although it was found out few errors in their 
written work. Yet, few other students relied too much on the use of a dictionary or translation application to search every single word to write which leads the students to need more time in doing the project in class. Some students translated everything by using Google Translate which resulted in the wrong grammatical structure. At the end of the project, it was found out that the students who relied too much on Google Translate and were often lacking time were those who rarely participated during the InstaGlish project in the cycle 2. Meanwhile, the students who actively participated in cycle 2 did not find much difficulty in writing captions in class although there were still some errors made. During the class, these students also actively asked questions during the process of creating captions in class such as how to choose the most suitable vocabulary so that it conveyed what they really meant. Sometimes, they simply confirmed if their ideas and sentences were correct.

Cycle 3 was also analyzed from three aspects which were grammar, mechanics, and content. From the grammar, it was found out that the same errors were repeated such as sentence structure (28\%), subject and verb agreement (22\%), and verb vs auxiliary verb (19\%). However, less errors were found in students who were active in InstaGlish in the cycle 2. In terms of conjunctions, there was a significant improvement with only $5 \%$ errors. In terms of mechanics, there were found errors in terms of capitalization with $35 \%$ of the students still using small-case letters in the beginning of the sentences. Misspelling was also found in $31 \%$ errors and punctuation was 25\%. From the content, $96 \%$ of the students stayed within the topic by elaborating the pictures shown, whether it was describing or telling a story related to the pictures. However, one student's work did not have any connection with a picture in Cycle 3.

After analyzing the result of Cycle 3, the improvement was shown in the students' work compared to previous cycles in terms of grammar, content, and mechanics. In addition, $72 \%$ students were active in consulting with the researchers especially when they did peerassessment in the classroom. Students were also actively consulted through adun instant messenger, WhatsApp. From students' score, it was figured out that $87.5 \%$ of the students reached the minimum passing grade with $12 \%$ students got $\mathrm{D}, 44 \%$ got $\mathrm{B}, 25 \%$ got $\mathrm{B}+$, and $19 \%$ got A.

\section{Summative Assessment}

After going through the three cycles of project implementation, the researchers conducted the summative assessment to investigate how effective the implementation of InstaGlish project toward students' English improvement. The summative assessment was in 
the form of final exam of semester rather than discrete exam as the researchers aimed at giving the normal class situation as their daily. Students had to answer set of questions and they were also asked to write two paragraphs with around six sentences for each paragraph. In the writing session, students were given two topics and they chose one topic only. During the final exam, some of the students were late for 10-20 minutes which led to the lack of time for them to complete the test, especially the writing section. Although there was a privilege that students could use of dictionary during the final exam, some students still could not finish writing two paragraphs. Some of them finished one paragraph while some others did two paragraphs.

Furthermore, there was no significant problem of the content aspect, yet there were still errors in grammar and mechanics aspects such as from sentence structure (31\%), subject and verb agreement (24\%), and conjunction (17\%), capitalization (37\%), spelling (31\%), and punctuation (21\%). Some sentences were so noticed to have a very 'Indonesian' style like it was directly translated to English. From the students' writing score, it was found out that $26 \%$ did not reach minimum passing grade C. Eventually, it was concluded that InstaGlish affected students' English performance by showing the improvement, especially for writing skill. The satisfying result was noticeable from the students who showed high motivation to do the projects in every cycle and to be actively involved in asking questions inside and outside the classroom.

\section{InstaGlish Project vis a vis Its Potential Use in the Classroom Contexts}

In the project of InstaGlish, the researchers made use of the application within the EFL coverage which is in line with a number of studies supporting the benefits of social media. It is very potential in providing digital learners to enable learners and instructors to communicate, have dialogue, exchange ideas that promote cooperation and collaboration (Greisemer, Dunn, 2012).

Despite all benefits, there are still some cons on the use of it within the teaching and learning process, such as distraction, cyberbullying, and face-to-face communication discouragement. Regarding to these concerns, it should be underlined that this current InstaGlish project was applied to the college students whose range age is 18 - 20 that can be categorized as mature age to be given a responsibility to be a wise user of social media so that in the implementation process the points of cons stated previously did not happen. The tips for the future researchers to prevent the distraction during teaching and learning process is to consider the age of the students and essential agreement could be set at the beginning of the 
class on the point of how students could use gadgets during the class. The essential agreement set together will also teach the students to be responsible and committed toward the rules agreed.

InstaGlish also bridges the high interest of today's millennial youth of social media, in this case Instagram, and English skills that students have to achieve. InstaGlish also facilitates students who are uncomfortable or have low confidence to speak up directly in the classroom by expressing their ideas through uploading pictures and giving captions as well as commenting to others' images. A shy student who neither stood in front of the class to tell her opinion nor asked the questions to the researchers during the class, showed that she could express ideas well although the grammar was not fully correct. Thus, it can be concluded that InstaGlish or social media assisted learning is potential to facilitate students with introverted/shy personalities.

Regarding the opinion that social media will reduce the valuable lessons of real-life social skills, InstaGlish project still concerns it; proven by the chosen topics throughout the project were close to the students' life. This way can be used to balance the virtual as well as real social interaction among students. Further the topics were also carefully chosen as contextual as the real-life issues which happen in students' surrounding. So, it could be concluded that the use of social media does not always reduce social skill or is far from real life contexts.

In the project of InstaGlish, students can learn language through the activities which are fun for them. InstaGlish also increases students' vocabulary as they have to make a caption in English which makes the students to be attentive towards the word spelling. Making captions through InstaGlish project will improve students' writing skill for it gives exposure to the students to write. During the implementation of the InstaGlish project, few students were absent during classes and they did not participate in the project; even after the researchers encouraged them to do the late-post. The researchers also provided a consultation session after the class or outside the class via Direct Message (DM) in Instagram to the students, face to face meeting as well as using Whats App to support the consultation but only few students did it. These kinds of ways then gave the insight that using social media can ease teacherstudent communication. Moreover, many features enable us to send voice notes, pictures, videos, and documents.

However, there were drawbacks coming from this online-consultation. The most inconvenient factor was the vague context of the questions from the sender (students); sometimes, the students did not express their questions clearly and only asked a few words in Indonesian to be translated to English without giving the clear context of the sentences. Thus, 
the teacher always confirmed what the students really wanted to express. Another apparent problem from online consultation was from the inefficient timing. As there was no exact time for the students to have a consultation with the teacher, sometimes the students' messages could not be replied instantly after the students sent the messages which delayed the consultation for a while. Regardless of all the challenges faced by the researchers during the implementation of InstaGlish project, the students stated that the application of InstaGlish as the supplementary tasks they have to do outside the class has brought improvement of their English ability proven by $88.2 \%$ of the students said yes on the questionnaire.

\section{InstaGlish Project: Look Closer to its Challenges}

During the implementation of InstaGlish, a number of challenges were found out, for instance students' unpunctuality in handing in the tasks due the difficulty in creating caption and choosing pictures to post. Having three pictures to post in a week and a six-sentencecaption for one post could be hard for students. Despite the difficulty both the students and researchers faced, the researchers could utilize various strategies to help the implementation of InstaGlish project, it could be graphic organizer, brainstorming discussion, or questioning technique. The students are expected to have more practice as language acquisition is a kind of skill, the more it is used, the more fluent the users are.

The other challenge in the project of InstaGlish is the ideas on what caption on the pictures uploaded. Students are still difficult to write as they lack vocabulary and low writing habits. In addition, for non-English department students, comprehension difficulty due to unfamiliar words is the major challenge. The use of Google Translate is also a challenge for project implementation. There are many students only copied and pasted the sentences, paragraph, or essay in Google Translate box, and were instantly given the translation in English. The students were also found to make errors in constructing the sentences as they fully adopted the idea of creating sentences in Indonesia to English. Al-Zuoud (2013) mentioned that one type of errors in students' written work is because they adopt their L1 (native language) when they are using the target language. This theory is supported by the fact that the students wrote the English words based on how they speak in Indonesian. Consequently, the students are not able to write the actual correct words.

The condition was also strengthened by the students' low confidence as well as motivation in using English. In order to trigger students' motivation, the researchers apply competition strategy by giving prizes for the ones who got the Best Pictures, Best Caption, and Most-Liked Picture which are expected to be extrinsic motivation for students to improve their 
performance. However, the trigger was not fully effective to make students' more active in the project as their intrinsic motivation has been low. It is in the contrary with the theory that prize can be the extrinsic motivation for students. The college students with a range of ages 18 - 20 need something more than a prize.

Furthermore, the caption that is obtained from literal translation Indonesian - English from Google Translate sometimes does not make sense. It could have happened as students did not read what they got from the translator machine. This is a proof of low reading motivation for Indonesian students. In fact, Indonesia is the 60th out of 61 countries in terms of literacy rank on the survey conducted by Most Literate Nations in the World in March 2016. UNESCO finding also figured out that Indonesian reading rate level is 0.001 . In addition, the national library also stated that in 2015 reading literacy rate of Indonesia is only 25.1 categorized as low (Munir, 2016).

As the college students, learners are expected to become autonomous in their learning experiences so that they are able to use available resources freely and make their own learning plans in order to achieve educational goals. Teachers also have to be more autonomous to provide effective learning opportunities to develop students' potential to improve themselves. The development of technology has facilitated the learning process from teachers as the main figure to student-centered learning. It is in line with the constructivist learning model in which students take more responsibility for their learning journeys as autonomous learners (Holec, 1981 in Gardner 2011) so that it can be said that autonomous students are active as well as motivated learners (Ushioda 1996 in Gardner 2011). They have high intrinsic motivation as well as the skills of reflection to plan, monitor, and evaluate their own learning process.

\section{E. CONCLUSION}

Based on the application of InstaGlish, it was concluded that InstaGlish brings a positive atmosphere and new learning experiences toward the students as they could make use of social media as part of their learning media. In the present study, InstaGlish is effective in improving students' writing skills, especially related to the three main problems that the students face namely grammar, mechanics, and content. The implementation of cycle 1 and 2 were not effective due to the students' low participation in InstaGlish implementation. Moreover, it was found out that the error percentages in grammar and mechanics were still high. With a slight difference in cycle 3, it successfully improved both students' participation and lessened the error percentages of grammar, mechanics, and content aspects. The positive result, then, continued to the summative assessment where students created less grammatical 
errors and had no problem in terms of mechanics and content aspect.

InstaGlish is also categorized out of box teaching strategies to promote students' autonomous learning during as well as outside the class. The application of this project also trains the students to learn how to be committed and responsible toward the tasks they have. Eventually, after the application of the InstaGlish project, it is clearly seen the improvement of students in their English skill, particularly writing as they are exposed to practice their writing during the project.

Despite all the positive points InstaGlish has, there are still many challenges in the implementation of InstaGlish which leads to a number of suggestions toward future researchers. Students were having difficulty to post three pictures in a week as well as create a six-sentence caption for one post so that it is suggested that prospective teachers/researchers investigate students' foreign language ability prior to implementing InstaGlish project which the result would be used to determine how many pictures that should be uploaded, probably one in a week would be the best. In addition, it is crucial to insert the awareness of paraphrasing ability in order to prevent plagiarism. Teachers as well as lecturers also need to insert it within the course and start to apply using tools, such as turnitin to check students' work originality.

\section{REFERENCES}

Al-Zuoud, K.M. (2013). Investigating Jordanian EFL Students' Spelling Errors at Tertiary Level. International Journal of Linguistics, 5(3), 164-176.

Aslam, S. (2017). Instagram by the Numbers: Stats, Demographics, and Fun Facts. Retrieved April 10, 2017, from https://www.omnicoreagency.com/instagram-statistics/.

Asosiasi Penyelenggara Jasa Internet Indonesia. (2016). Penetrasi dan Perilaku Pengguna Internet Indonesia: Survei 2016. https://apjii.or.id/downfile/file/surveipenetrasiinternet2016.pdf

Belal, A. (2014). Influence of Digital Social Media in Writing and Speaking of Tertiary Level Student. BRAC University. Retrieved on April 20, 2021, from https://core.ac.uk/download/pdf/61808239.pdf

CCSU News Release. (2016). World's Most Literate Nations Ranked [Press Release]. https://webcapp.ccsu.edu/?news $=1767 \&$ data

Cunningham, J. (2014). Using Instagram in the Classroom: Five Activities. Retrieved April 22, 2017, from https://www.educationworld.com/a_tech/instagram-classroom-student-activityideas.html.

Daryanto. (2013). Instructional Media: The Roles on Reaching Learning Goals. Yogyakarta: Gaya Media. 
Pusfika, Ika, Instaglish: When Instagram...

Dunn, L.A. (2012). Teaching in Higher Education: Can Social Media Enhance the Learning Experience? $\quad$ Retrieved, June 16, 2017, from http://www.gla.ac.uk/media/media_276225_en.pdf.

Erarslan, A. (2019). Instagram as an Education Platform for EFL Learners. TOJET: The Turkish Online Journal of Educational Technology, 8(3), 54-69. accessed on April 24, 2021. Retrieved from https:// files.eric.ed.gov/fulltext/EJ1223776.pdf

Ferreira, L.H.F. (2007). How to Teach Vocabulary Effectively: An analysis of the Course Book. Eyes and Spies. Retrieved May 5, 2017, from http://www.portaldoconhecimento.gov.cv/bitstream/10961/2431/1/lastversion.pdf.

Gardner, D. (2011). Fostering Autonomy in Language Learning. Turkey: Zirve Universites

Greisemer, J. A. (2014). Using Social Media to Enhance Students' Learning Experiences. Quality Approaches in Higher Education, 3(1), 8-11.

Handayani, F. (2016). Instagram as a Teaching Tool? Really?. Proceedings of the Fourth International Seminar on English Language and Teaching (ISELT-4). accessed on April 14, 2021, from http://ejournal.unp.ac.id > selt > article > download

Katey. S. (2015). Everytbing You Need to Know about Teaching with Instagram. Retrieved May 5, 2017, from http://www.avatargeneration.com/2015/01/everything-you-need-to-knowabout-teaching-with-instagram/.

Lonka, K, et al. (2015). Innovative Schools: Teaching \& Learning in the Digital Era. Brussels: European Union.

Manaroinsong, M. (2018). The Use sof Instagram as Mobile Learning to Support English Cognitive Learning Process. Unpublished thesis. Retrieved on April 24, 2021 from https://dspace.uii.ac.id/bitstream/handle/123456789/13618/SKRIPSI\%20MERY\%20 MANAROINSONG\%2013322005.pdf?sequence $=1 \&$ isAllowed $=\mathrm{y}$

McKay S. L. (2006). Researching Second Language Classrooms. New Jersey: Lawrence Erlbaum Associates Inc.

Musfiqon. (2012). Development of learning media and sources. Jakarta: Prestasi Pustakaraya.

Munir, S. (2016, April 28). Minat Baca Rendah, Mayoritas Warga Indonesia Hobi Nonton Televisi. Kompas.

http://regional.kompas.com/read/2016/04/28/21020061/Minat.Baca.Rendah.Mayorit as.Warga.Indonesia.Hobi.Nonton.Televisi.

Pikulski, J.J. \& Templeton, S. (2004). Teaching and Developing Vocabulary: Key to LongTerm Reading Success. Houghton Mifflin Reading. Retrieved June 30, 2017, from https://www.eduplace.com/marketing/nc/pdf/author_pages.pdf.

Puspitarini, Y.D. \& Hanif, M. (2019). Using Learning Media to Increase Learning Motivation in Elementary School. Anatolian Journal of Education, 4(2), 53-60.

Rayuningtya, P. (2013). Using of K-W-L Strategy to Improve the Reading Comprehension of the Seven Graders of SMP Negeri 8 Malang [Unpublished Master's Thesis]. Universitas Negeri 
Volume 7, Number 01, June 2021

Malang, Jawa Timur, Indonesia.

Tankovska, H. (2021). Most popular social networks worldwide as of January 2021, ranked by number of active users (in millions). Statistica. Accessed April 14, 2021, from https://www.statista.com/statistics/272014/global-social-networks-ranked-by-numberof-users /

Teti, A et al. (2016). Translating Theory of English into Indonesian and Vice-Versa. Indonesian Journal of English Language Studies, 2(1), 39-58. 